\title{
Chk1/2 inhibitor AZD7762 blocks the growth of preantral follicles by inducing apoptosis, suppressing proliferation, and interfering with the cell cycle in granulosa cells
}

Xiao-ming Liu ( $\square$ lxm19860405@163.com )

Yuying Children's Hospital of Wenzhou Medical College: Wenzhou Medical University Second Affiliated Hospital https://orcid.org/0000-0002-7062-2468

\section{Fang Chen}

Wenzhou Medical College - Chashan Campus: Wenzhou Medical University

\section{Fan Zhang}

The Second Affiliated Hospital and Yuying Children's Hospital of Wenzhou Medical University Jun-Zhao Zhao

Wenzhou Medical University Second Affiliated Hospital

\section{Research Article}

Keywords: checkpoint kinases 1/2, follicular development, apoptosis, proliferation, cell cycle

Posted Date: January 21st, 2022

DOI: https://doi.org/10.21203/rs.3.rs-1275321/v1

License: (c) (i) This work is licensed under a Creative Commons Attribution 4.0 International License.

Read Full License 


\section{Abstract \\ Background}

Checkpoint kinases 1/2 (Chk1/2) has an important role in somatic cells development and oocyte meiotic maturation. However, the role of Chk1/2 in folliculogenesis has not been fully elucidated. The aim of this study was to assess the effects of Chk1/2 inhibition on ovarian folliculogenesis and granulosa cells development in mice.

\section{Methods}

Preantral follicles $(100 \mu \mathrm{m}-120 \mu \mathrm{m})$ and granulosa cells from pre-ovulatory follicles (pre-GCs) of mice were isolated and cultured with or without Chk1/2 inhibitor AZD7762. Preantral follicles were cultured for $96 \mathrm{~h}$. Then, follicle morphology and follicular growth were assessed every $48 \mathrm{~h}$. Granulosa cells were cultured for $48 \mathrm{~h}$ with or without AZD7762, after which cell apoptosis, cell proliferation, and cell cycle analysis were assessed; meanwhile, the mRNA expression of PCNA and Bax were measured by real-time RT-PCR, and PCNA and Bax protein were measured by Western blot.

\section{Results}

Compared with control follicles, AZD7762 inhibited growth of preantral follicles. Furthermore, inhibition of Chk1/2 significantly induced apoptosis and inhibited the proliferation of granulosa cells, arrested cell cycle at S and G2/M phases, and decreased G1 phase fraction. Also, the expression of PCNA mRNA and protein were significantly reduced, while Bax mRNA and protein were significantly increased post AZD7762 treatment in granulosa cells.

\section{Conclusions}

This study revealed that Chk1 and Chk2 have a crucial role during preantral follicular development by regulating the proliferation and apoptosis of granulosa cells.

\section{Introduction}

In mammals, oocytes arrested in the diplotene stage of the first meiotic prophase are surrounded by a single, squamous layer of somatic cells to form a finite population of non-growing primordial follicles [1]. Primary follicles are recruited from the primordial pool as oocytes grow. These cells continue to proliferate to form many layers surrounding the oocyte and eventually become granulosa cells [2]. This transition is associated with participation in the subsequent phases of follicular growth, as the measured recruitment of primordial follicles from the resting pool of follicles is crucial for the development of folliculogenesis throughout the reproductive lifespan of mammals [3]. However, apoptosis reduces this 
endowment by two-thirds before birth. In addition, granulosa cells apoptosis is the main cause of follicular atresia at different stages of their growth $[4,5]$.

When atresia occurs, pyknotic nuclei are first observed in granulosa cells. Then a detachment of granulosa cell layer and fragmentation of basal membrane occurs, ultimately resulting in hypertrophied thecal cells and disruption of thecal integration and thecal vessels [6]. Granulosa cell apoptosis may occur much earlier than the morphological changes in follicular atresia, which can be observed only when granulosa cell apoptosis reaches a certain degree [7]. Generally, proliferation and differentiation of granulosa cells lead to follicular maturation and ovulation, whereas apoptosis and degeneration of granulosa cells result in follicular atresia [8]. Many apoptosis-related factors have been implicated in follicular atresia, including death ligands and receptors, intracellular pro- and anti-apoptotic molecules, cytokines, growth factors, and several apoptosis-related genes [9]. Although new regulatory factors are continuously being identified, comprehensive knowledge of the signaling networks that function during granulosa cell apoptosis remains limited.

Checkpoint kinases are threonine/serine that can be divided into two subtypes, Chk1 and Chk2, which have a critical role in DNA damage responses, cell cycle control, and cell survival [10]. In response to DNA damage, Chk1 and Chk2 are activated by PI3 kinase-related kinases ATM and ATR, respectively, aiming at many downstream substrates that coordinate cell cycle checkpoint activation, DNA restitution, and apoptosis [11]. Moreover, Chk1/2 has also been implicated in anaphase entry, chromosome condensation, and maintenance of genome integrity in somatic cells in the absence of DNA damage [12]. Chk1 knockout mice are embryonically lethal, suggesting that Chk1 is an important molecule during early embryonic development [13]. Moreover, embryonic stem cells specific Chk1 knockout mice display premature activation of $\mathrm{Cdc} 2 /$ cyclin B and mitotic catastrophe [14]. At the same time, Chk2-deficient cells show significant defects in UV-induced apoptosis and G1/S arrest [15]. Preliminary unpublished observations from our laboratory showed that the expression of Chk $1 / 2$ fluctuates during follicular development, suggesting the importance of Chk1/2 in folliculogenesis; yet, the exact role in follicular development is not fully understood.

In the present study, Chk1/2 inhibitor (AZD7762) was used to further investigate the role of Chk1/2 during preantral follicular development and cellular proliferation and apoptosis.

\section{Materials And Methods}

\section{Animals}

Female Kunming white mice of 12-14 (9 g-10 g) or 21-23 (12 g-14 g) days old were obtained from the Centre of Laboratory Animals of Hubei Province (Wuhan, PR China). Mice were housed in an environment with a temperature of $24 \pm 1^{\circ} \mathrm{C}$, relative humidity of $50 \pm 1 \%$, and a light/dark cycle of $12 / 12 \mathrm{hr}$, and given food and water ad libitum. All animal studies (including the mice euthanasia procedure) were done in compliance with the regulations and guidelines of the Hubei Research Center of Experimental Animals 

0005).

\section{Isolation and culture of preantral follicles and granulosa cells}

Preantral follicles $(100 \mu \mathrm{m}-120 \mu \mathrm{m})$ obtained from the ovaries of 12-14 days old female mice were gently separated using the $1 \mathrm{ml}$ syringe needle under a stereomicroscope (CKX41SF; Olympus Optical Technology Philippines Inc., Lapu-Lapu City, Philippines), and observed under an inverted microscope (TE2000-U; Nikon). Follicles with two or three layers of granulosa cells and a diameter between 100 and $120 \mu \mathrm{m}$ were collected and cultured in a- Minimum Essential Media (a-MEM, Gibco) containing $10 \mu \mathrm{g} / \mathrm{mL}$ of ITS ( $0.55 \mathrm{mg} / \mathrm{mL}$ human transferrin, $1.0 \mathrm{mg} / \mathrm{mL}$ recombinant human insulin, and $0.5 \mu \mathrm{g} / \mathrm{mL}$ sodium selenite) and $100 \mathrm{mlU} / \mathrm{mL}$ of follicle-stimulating hormone (FSH, Sigma Chemical Company, St. Louis, MO) with one follicle per well in 96-well culture plates in a humidified atmosphere containing $5 \% \mathrm{CO}_{2} / 95 \%$ air at $37^{\circ} \mathrm{C}$ for $48 \mathrm{~h}$. After that, follicles were cultured in a-MEM medium containing ITS with or without $1 \mu \mathrm{M}$ of AZD7762 (Axon Medchem BV, Cat. No. Axon 1399) for an additional $96 \mathrm{~h}$ and observed under microscopy (TE2000-U; Nikon) for assessment of morphology and follicular growth, as indicated by follicular diameter (F.D). The concentration of the Chk1/2 inhibitor used in our study was selected based on previous study results [16].

GCs from pre-ovulatory follicles (pre-GCs) were taken from ovaries of 21-23 days old mice injected with $10 \mathrm{IU}$ pregnant-mare serum gonadotropin (PMSG, SanSheng, Ningbo) for 44-48 h and cultured as previously described [17]. Briefly, granulosa cells were cultured in Dulbecco's Modified Eagle's Medium/Nutrient F-12 (DMEM/F12; Gibco) medium with 10\% fetal bovine serum (FBS; Invitrogen), 100 $\mathrm{U} / \mathrm{mL}$ penicillin, and $100 \mu \mathrm{g} / \mathrm{mL}$ streptomycin (Gibco). All cultures were maintained in DMEM/F12 medium in a humidified atmosphere containing $5 \% \mathrm{CO}_{2} / 95 \%$ air at $37^{\circ} \mathrm{C}$.

\section{Cell proliferation assay}

Cell proliferation assay was measured using a WST-1 Cell Proliferation Assay kit (Beyotime, Wuhan, China). Briefly, granulosa cells were cultured in a 96-well culture plate $\left(4 \times 10^{3}\right.$ cells/well) for $24 \mathrm{~h}$. Cells were then exposed to a gradually increased concentration of $\operatorname{AZD7762}(1,5,10,20$, and $50 \mu \mathrm{M})$ for $24 \mathrm{~h}$, $48 \mathrm{~h}$, and $72 \mathrm{~h}$. After each time point, $10 \mu \mathrm{l}$ of freshly prepared WST-1 solution was added to each well, along with the culture medium. The absorbance of the samples was measured after $1 \mathrm{~h}$ at $37^{\circ} \mathrm{C}$ using a microplate reader (Bio-Rad Laboratories, Inc., Hercules, CA, USA) at $450 \mathrm{~nm}$.

\section{Cell cycle assay}


For cell cycle analysis, pre-GCs were cultured in a 6-well culture plate with $0 \mu \mathrm{M}$ or $1 \mu \mathrm{M}$ AZD7762 for 48 h. After being washed with PBS, the cells were digested and harvested using the Cell Cycle Detection kit (KeyGen Biotech Co., Ltd., Nanjing, China). Cells were then fixed in $70 \%$ ethanol at $4^{\circ} \mathrm{C}$ overnight, washed with PBS, and incubated with $100 \mu \mathrm{L}$ RNase $A$ at $37^{\circ} \mathrm{C}$ for $30 \mathrm{~min}$. Then, the cells were stained with 400 $\mu \mathrm{L} \mathrm{PI}$ in the dark for $30 \mathrm{~min}$ at $4^{\circ} \mathrm{C}$ and analyzed through flow cytometry using a BD FACS Calibur [excitation wavelength (Ex), $488 \mathrm{~nm}$; emission wavelength (Em), $530 \mathrm{~nm}$; Becton-Dickinson, Mountain View, CA, USA].

\section{Cell apoptosis assay}

Pre-GCs were cultured in 6-well culture plate by adding $0 \mu \mathrm{M}$ or $1 \mu \mathrm{M}$ AZD7762 for $48 \mathrm{~h}$. After being washed in PBS, cells were digested and harvested. Annexin V-FITC/PI kit (AntGene, Wuhan) was used to detect the proportion of apoptotic cells according to manufacturer's instructions. Cells were incubated in AnnexinV-FITC and PI solution at room temperature in the dark for $15 \mathrm{~min}$, after which a $300 \mu \mathrm{L}$ of $1 \times$ binding buffer was added to each sample. Flow cytometric analysis was planned through a BD FACS Calibur (Becton, Dickinson and Company, USA; Ex, $488 \mathrm{~nm}$ and Em, $530 \mathrm{~nm}$ ). Cells that stained positive for annexin V-FITC were calculated as apoptotic cells.

\section{RT-PCR analysis}

RT-PCR analysis was performed to confirm that inhibition of Chk1/2 by AZD7762 could regulate genes expression, PCNA, and Bax. Pre-GCs were cultured with $0 \mu \mathrm{M}$ or $1 \mu \mathrm{M}$ AZD7762 for $48 \mathrm{~h}$, after which a total RNA was extracted using the RNAprep pure Cell/Bacteria Kit (TIANGEN, Beijing), and in vitro transcription was performed through RevertAid ${ }^{\mathrm{TM}}$ First-strand cDNA Synthesis kit (Thermo, Wuhan). RTPCR was quantified using special primer pairs (Table 1) and QuantiFast ${ }^{\circledR}$ SYBR $^{\circledR}$ Green RT-PCR kit (QiaGen, Wuhan) on the Roche LightCycler ${ }^{\circledR} 480$ according to manufacturer's instructions. The gene expression results were normalized to the basal level of $\beta$-actin. The $2^{-\Delta \Delta \mathrm{Ct}}$ was used to calculate the relative fold change of each gene.

Table 1. RT-PCR primer pairs

\begin{tabular}{cll}
\hline Genes & & \multicolumn{1}{c}{ Primer sequences } \\
\hline PCNA & Forward & AGACAGTGGAGTGGCTTTT \\
& Reverse & CCGAGACCTTAGCCACATT \\
Bax & Forward & CCAGGATGCGTCCACCAA \\
& Reverse & CAAAGTAGAAGAGGGCAACCAC \\
\multirow{3}{*}{-actin } & Forward & CCCATCTACGAGGGCTAT \\
& Reverse & TGTCACGCACGATTTCC \\
\hline
\end{tabular}




\section{Western blot}

After AZD7762 treatment for 48 h, cells were harvested in RIPA buffer (Santa Cruz), which contained 10 $\mathrm{mg} / \mathrm{mL}$ protease inhibitors cocktail (Santa Cruz) and $10 \mathrm{mM}$ phenylmethylsulfonyl fluoride (PMSF; DingGuo, Beijing). The concentration of total protein was determined by bicinchoninic acid (BCA) assay (Pierce, Rockford, USA), and $20 \mathrm{mg}$ of total protein was subjected to gel electrophoresis as previously described [17]. Monoclonal mouse anti- $\beta$-actin IgG (1:1000 dilution; Santa Cruz), monoclonal mouse antiPCNA IgG (1:600 dilution; Santa Cruz), and monoclonal rabbit anti-Bax IgG (1:1000 dilution; EPI) were used as the primary antibody, and HRP-conjugated anti-mouse or rabbit secondary antibodies (1:2000 dilution; Boster, Wuhan) were used. The images were measured with a Gel-Pro analyzer 4.0 (Media Cybernetics, Silver Spring, MD, USA). The scanning intensities of the Western blots were analyzed using Image J software to quantify the target bands compared to the corresponding $\beta$-actin bands.

\section{Statistical analysis}

Experiments were independently performed at least three times, and data are presented as mean $\pm S D$. Differences between each group were analyzed by one-way ANOVA followed by Tukey's Honesty Significant Difference (HSD) test using SPSS (Version 17.0; SPSS, Chicago, IL, USA); $P<0.05$ was regarded as a statistically significant difference.

\section{Results}

\section{Chk1/2 are essential for preantral follicular development}

In order to assess the role of Chk1/2 during follicular development, we cultured preantral follicles with Chk1/2 broad-spectrum inhibitor (AZD7762) in vitro. In the control group, the gradual growth of follicles was observed, while follicles cultured with AZD7762 showed no growth or cell number reduction (Figure $1 \mathrm{~A}$ and $1 \mathrm{~B}, \mathrm{P}<0.05)$. Meanwhile, as shown in Figure $1 \mathrm{C}$, the granulosa cells of follicles treated with AZD7762 around the outer layer showed cell shrinkage and weak connection between cells compared with the control follicles. Thus, we predicted that the arrested development of preantral follicles and abnormalities of the morphology of follicles might be related to the granulosa cells status, including proliferation and apoptosis.

\section{Inhibition of Chk1/2 induces granulosa cells apoptosis}

As shown in Figure 2A, granulosa cells cultured with AZD7762 showed abnormal cell morphology. As seen in Figure 2B, the apoptosis rate in the AZD7762 group was significantly higher than in the control 
group $(P<0.05)$. In addition, the expression of Bax, a marker of apoptosis, was significantly up-regulated in both mRNA and protein levels (Figure $2 \mathrm{C}$ and $2 \mathrm{D}, \mathrm{P}<0.001$ and $P<0.05$ ).

\section{Inhibition of Chk1/2 reduces granulosa cell proliferation}

In order to study whether Chk1/2 affect granulosa cells' proliferation, cells were cultured with different concentration of AZD7762 for 24,48 , or $72 \mathrm{~h}$, respectively. When cells were cultured for $24 \mathrm{~h}$, the percentage of proliferation was similar, and no significant difference between the control group and $1 \mu \mathrm{M}$ AZD7762 was seen ( $P>0.05)$; yet, the percentage of proliferation was significantly reduced when cells were treated with a higher concentration of $\operatorname{AZD} 7762(5,10,20$, and $50 \mu \mathrm{M}, P<0.01$, Figure 3A). However, after 48 or $72 \mathrm{~h}$, the percentage of proliferation was also significantly reduced in $1 \mu M$ AZD7762 (Figure $3 A, P<0.01)$, while no significant difference was found among a higher concentration of AZD7762 $(5,10$, 20 , and $50 \mu \mathrm{M}$, Figure $3 \mathrm{~A}$ )

In addition, RT-PCR was applied to detect the expression level of PCNA, which is a marker of proliferation. After culturing cells with AZD7762 for $48 \mathrm{~h}$, the expression of PCNA mRNA was significantly decreased compared with control cells (Figure 3B, $\mathrm{P}<0.01$ ). Furthermore, Western blot results also showed decreased expression of PCNA protein in AZD7762 cultured cells (Figure 3C, $\mathrm{P}<0.01$ ).

\section{Inhibition of Chk1/2 arrests cell cycle at S and G2/M stages}

Next, we explored the effect of Chk1/2 arrests cell cycle at S and G2/M stages. As shown in Figure 4, the percent of the G1 stage in the AZD7762 group was significantly lower than the control cells $(P<0.001)$, while the percent of $S$ and $G 2$ stages were significantly increased in the AZD7762 group than control $(P<0.001)$. Therefore, our results indicated that inhibition of Chk1/2 by AZD7762 could suppress the proliferation of cells and disturb the normal cell cycle. Taken together, inhibition of Chk1/2 resulted in inhibition of proliferation and promotion of apoptosis of granulosa cells.

\section{Discussion}

In this study, AZD7762 was used to inhibit the function of both Chk1 and Chk2. Preantral follicles treated with AZD7762 showed a developmental abnormality. Moreover, granulosa cells treated with AZD7762 showed decreased cell growth, increased apoptosis, and abnormal cell cycle distributions. These results suggest that Chk1/2 has an important role in preantral follicular development and the growth of granulosa cells.

The development of preantral follicles includes oocyte growth, granulosa cell proliferation, differentiation, and apoptosis. However, more than $99 \%$ of follicles disappear, primarily due to the apoptosis of granulosa cells, and the majority of follicles become atretic during the early antral stage of development [18]. Thus, we selected the preantral follicles in this experiment, which were then treated with a Chk $1 / 2$ inhibitor to monitor the follicular development. Activated Chk1 and Chk2 have a full spectrum of substrates that are key cell cycle regulators. In the control group, the gradual growth of follicles was 
observed, while follicles cultured with AZD7762 showed no growth or even negative growth (Fig. 1). These results suggested that Chk1/2 is essential for follicular development.

Gonadotropin can promote the differentiation of the granulosa cells, making them vulnerable to apoptosis. Thus, pre-GCs were selected to study the role of Chk $1 / 2$ in regulating the development of granulosa cells. The cells treated with AZD7762 showed decreased cell growth and increased cell apoptosis (Fig. 2 and Fig. 3). Similarly, a previous study has suggested that Chk1 is required for mitotic progression and proliferation of Hela cells through negative regulation of polo-like kinase 1 Plk1 [19]. Meanwhile, Chk1-depleted lobuloalveolar mammary epithelial cells do not proliferate and undergo apoptosis, suggesting that cell proliferation is important for apoptosis [20]. Likewise, in our study, a proliferation of granulosa cells was significantly inhibited and showed an uncoordinated cell cycle (Fig. 4). The link between apoptosis and proliferation suggests that death resulting from Chk1 depletion may involve mitotic alteration [21]. However, in some circumstances, Chk2 appeared to be at least in part able to make up for the loss of Chk1 in some cells [22]. Our preliminary studies of Chk1/2 inhibition in mouse oocytes supported this hypothesis [23]. Moreover, the cell cycle of pre-GCs was disturbed by inhibition of Chk1/2 and showed increased G2 and S stages (Fig. 4). As Chk1/2 are the key cell cycle checkpoint kinase, and the major function of Chk1 is to coordinate the cell cycle checkpoint response, including G1, S, G2/M, and M phase [24], Chk2 is needed for the optimal G2/M delay of G2 phase cells; Chk2- deficient cells show G1/S arrest [25]. Our study showed that Chk1/2 might affect ovarian function by regulating the state (proliferation or apoptosis) of GCs and the fate (growth or atresia) of follicular development.

Future studies should investigate the exact function of Chk1 and Chk2 in follicular development and the regulatory mechanism of the Chk1/2 network responsible for follicular development. Studies have shown that Chk1 is a potential target for treating cancer [24], so another important issue is evaluating the possibility of Chk $1 / 2$ in reducing follicular atresia. Therefore, we propose that Chk $1 / 2$ could represent an option for suppressing follicular atresia.

\section{Conclusions}

Our present results provide insight into the roles of Chk1/2 in mouse ovaries, including follicular development, granulosa cells proliferation, and apoptosis. These results suggest that Chk $1 / 2$ may have an important role in follicular development and ovarian functions. Furthermore, future research on the security application of AZD7762 as drugs in clinical therapy of cancer (especially female patients) is warranted.

\section{Declarations}

\section{Funding}

This study was supported by the Natural Science Foundation of Zhejiang (Program NO. LQ18H040008). 


\section{Competing Interests}

There is no conflict of interest for all authors.

\section{Authors' contributions}

$\mathrm{XML}$ and $\mathrm{FC}$ conceived and designed the experiments. $\mathrm{XML}, \mathrm{FC}$, and $\mathrm{FZ}$ performed the experiments. $\mathrm{XML}$ and JZZ analyzed the data and wrote the manuscript. All authors reviewed the manuscript.

\section{Ethics approval}

All animal studies (including the mice euthanasia procedure) were done in compliance with the regulations and guidelines of the Hubei Research Center of Experimental Animals and conducted according to the AAALAC and the IACUC guidelines (Approval ID: SCXK (Hubei) 2008-0005).

\section{References}

1. Sen A, Caiazza F (2013) Oocyte maturation: a story of arrest and release. Front Biosci (Schol Ed) 5:451-477

2. Candelaria JI, Rabaglino MB, Denicol AC (2020) Ovarian preantral follicles are responsive to FSH as early as the primary stage of development. J Endocrinol 247(2):153-168

3. Rimon-Dahari $\mathrm{N}$ et al (2016) Ovarian Folliculogenesis. Results Probl Cell Differ 58:167-190

4. Zhou J, Peng X, Mei S (2019) Autophagy in Ovarian Follicular Development and Atresia. Int J Biol Sci 15(4):726-737

5. Findlay JK et al (2015) How Is the Number of Primordial Follicles in the Ovarian Reserve Established? Biol Reprod 93(5):111

6. Zhang $\mathrm{J}$ et al (2019) MicroRNAs in ovarian follicular atresia and granulosa cell apoptosis. Reprod Biol Endocrinol 17(1):9

7. Matsuda $\mathrm{F}$ et al (2012) Follicular growth and atresia in mammalian ovaries: regulation by survival and death of granulosa cells. J Reprod Dev 58(1):44-50

8. da Silva Bitecourt F et al (2018) Morphological study of apoptosis in granulosa cells and ovulation in a model of atresia in rat preovulatory follicles. Zygote 26(4):336-341

9. Khristi V et al (2018) ESR2 regulates granulosa cell genes essential for follicle maturation and ovulation. Mol Cell Endocrinol 474:214-226

10. Chen Y, Poon RY (2008) The multiple checkpoint functions of CHK1 and CHK2 in maintenance of genome stability. Front Biosci 13:5016-5029

11. Yang $\mathrm{H}$ et al (2017) Oxidative stress-induced apoptosis in granulosa cells involves JNK, p53 and Puma. Oncotarget 8(15):25310-25322

12. Chaurasiya $V$ et al (2020) Up-regulation of miR-326 regulates pro-inflammatory cytokines targeting TLR-4 in buffalo granulosa cells. Mol Immunol 119:154-158 
13. Schuler $F$ et al (2019) Checkpoint kinase 1 is essential for fetal and adult hematopoiesis. EMBO Rep 20(8):e47026

14. Niida H et al (2005) Depletion of Chk1 leads to premature activation of Cdc2-cyclin B and mitotic catastrophe. J Biol Chem 280(47):39246-39252

15. Tanoue $Y$ et al (2018) Differential Roles of Rad18 and Chk2 in Genome Maintenance and Skin Carcinogenesis Following UV Exposure. J Invest Dermatol 138(12):2550-2557

16. Dai XX et al (2014) Chk2 regulates cell cycle progression during mouse oocyte maturation and early embryo development. Mol Cells 37(2):126-132

17. Cao J et al (2018) SUMO2 modification of Aurora B and its impact on follicular development and atresia in the mouse ovary. Int J Mol Med 41(6):3115-3126

18. Hsueh AJ et al (2015) Intraovarian control of early folliculogenesis. Endocr Rev 36(1):1-24

19. Tang J, Erikson RL, Liu X (2006) Checkpoint kinase 1 (Chk1) is required for mitotic progression through negative regulation of polo-like kinase 1 (Plk1). Proc Natl Acad Sci U S A 103(32):1196411969

20. Lam MH et al (2004) Chk1 is haploinsufficient for multiple functions critical to tumor suppression. Cancer Cell 6(1):45-59

21. Okada H, Mak TW (2004) Pathways of apoptotic and non-apoptotic death in tumour cells. Nat Rev Cancer 4(8):592-603

22. Niida $\mathrm{H}$ et al (2010) Cooperative functions of Chk1 and Chk2 reduce tumour susceptibility in vivo. EMBO J 29(20):3558-3570

23. Liu XM et al (2021) Checkpoint kinases are required for oocyte meiotic progression by the maintenance of normal spindle structure and chromosome condensation. Exp Cell Res 405(2):112657

24. Zhang Y, Hunter T (2014) Roles of Chk1 in cell biology and cancer therapy. Int J Cancer 134(5):1013-1023

25. Nikitin PA et al (2014) Mitogen-induced B-cell proliferation activates Chk2-dependent G1/S cell cycle arrest. PLoS ONE 9(1):e87299

\section{Figures}



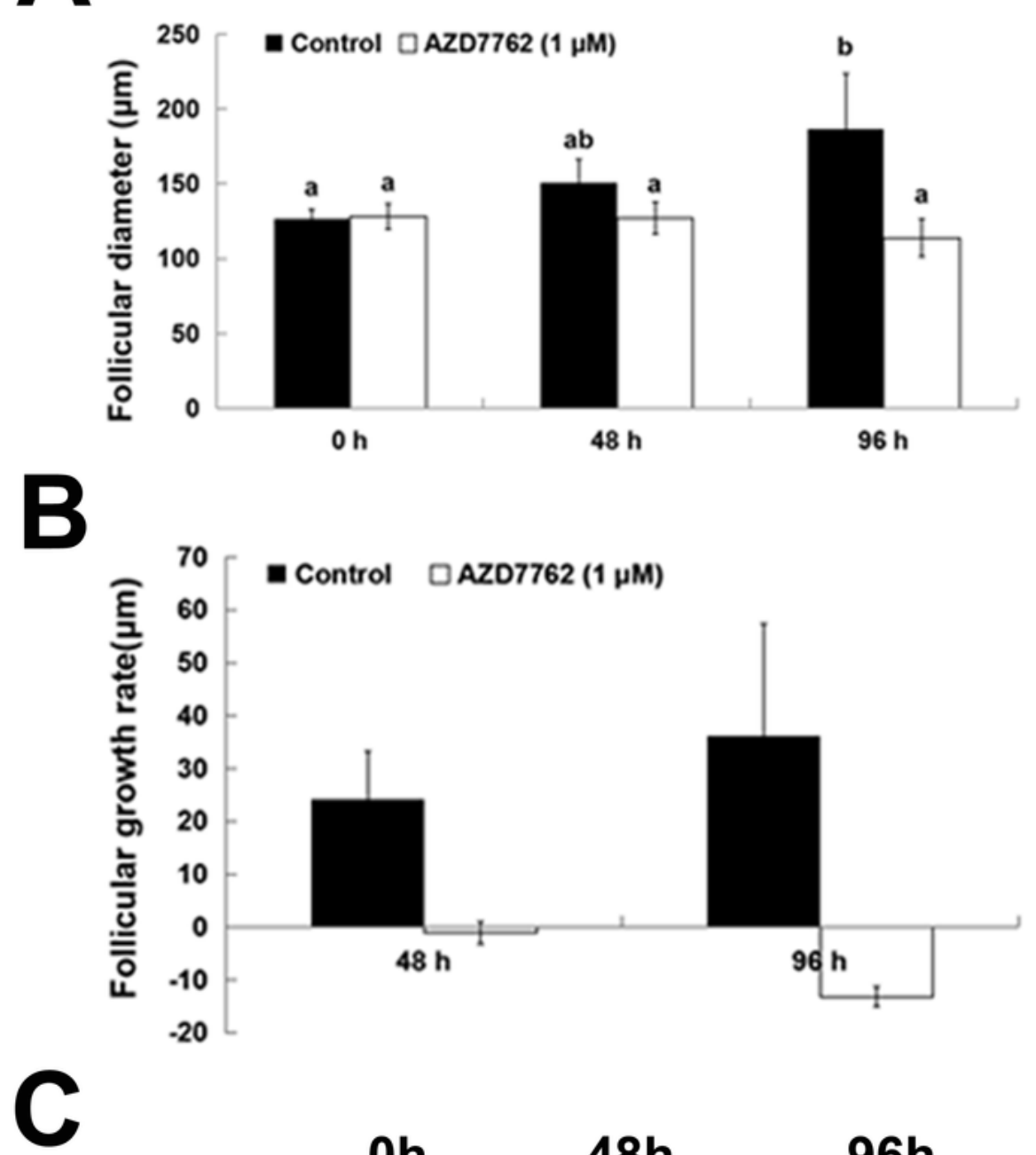

Control
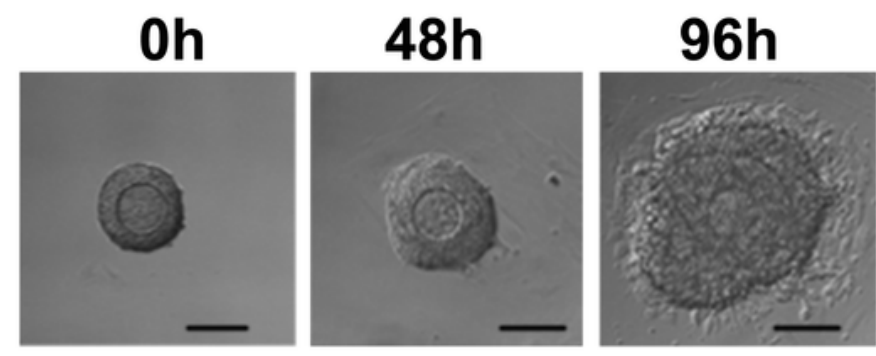

\section{$1 \mu \mathrm{M}$ AZD7762}
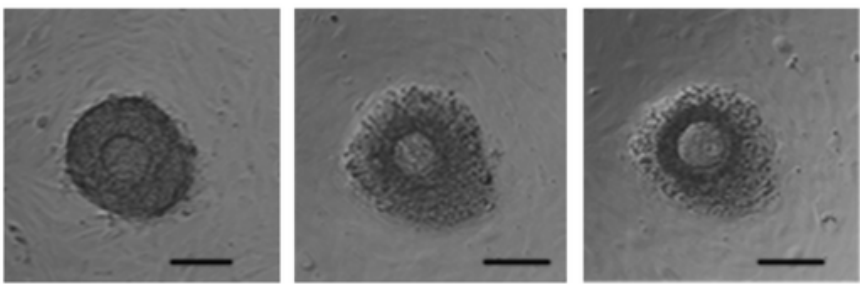

Figure 1

Inhibition of Chk1/2 blocks the development of preantral follicles in vitro. (A) Inhibition of Chk1/2 blocks follicular development. Follicles were cultured with $0 \mu \mathrm{M}$ or $1 \mu \mathrm{M}$ AZD7762 for $0 \mathrm{~h}, 48 \mathrm{~h}$, and $96 \mathrm{~h}$. Fifty follicles per set and the value expressed by each bar represent mean \pm SD. a vs. b, $P<0.05$. (B) The difference in follicular growth. The abscissa represents the time interval every $48 \mathrm{~h}$ of culture. (C) 
Abnormal morphology and structure of preantral follicles cultured with Chk1/2 inhibitor AZD7762. Scale bars, $100 \mu \mathrm{m}$.
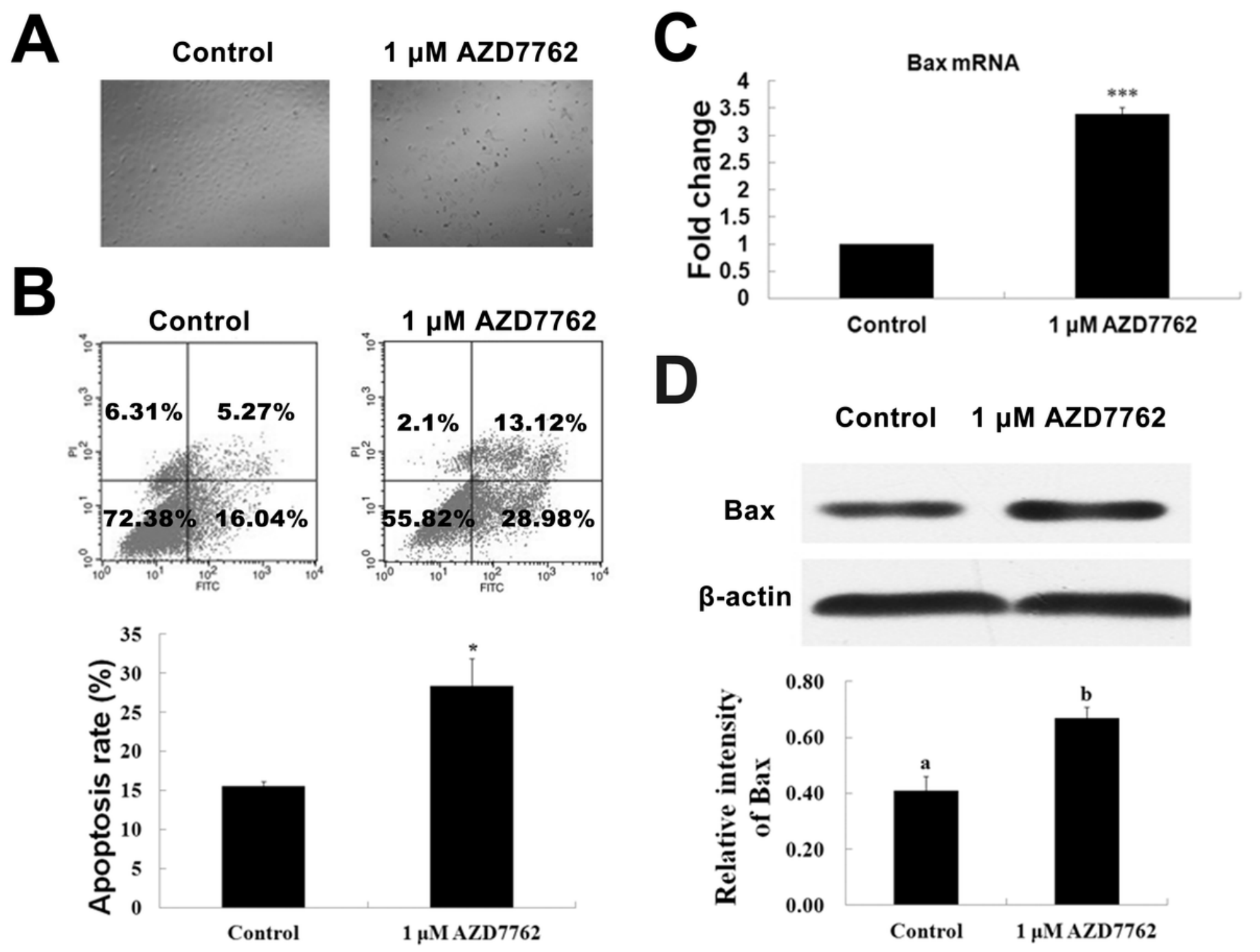

D

\section{Control $1 \mu \mathrm{M}$ AZD7762}
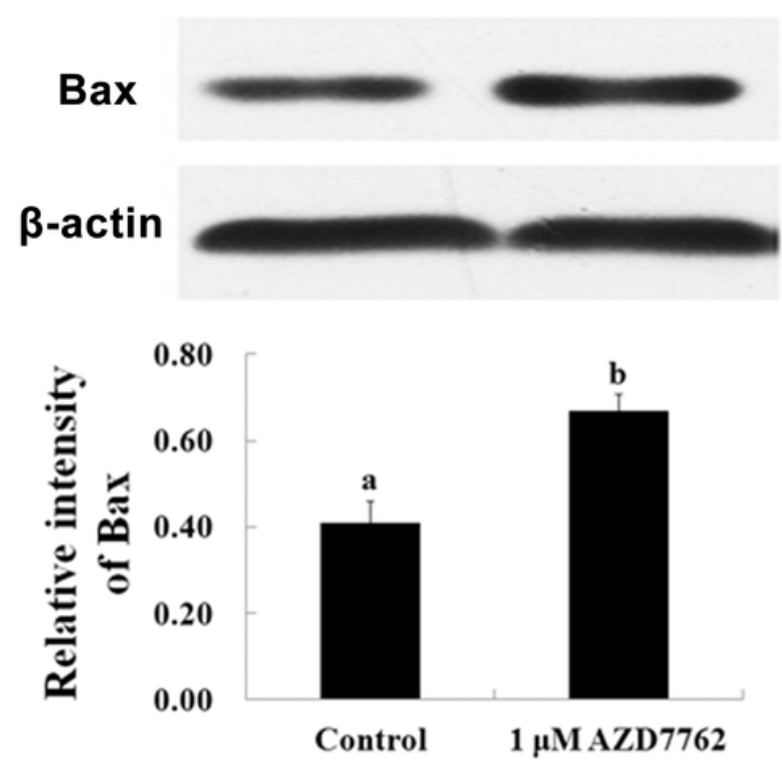

Figure 2

Inhibition of Chk1/2 led to apoptosis of granulosa cells in vitro. (A) Inhibition of Chk1/2 led to a contraction of the cytoplasm of cells during culture. (B) The apoptosis rate of pre-GCs cultured with $0 \mu \mathrm{M}$ or $1 \mu \mathrm{M}$ AZD7762 for $48 \mathrm{~h}$. The value expressed by each bar represents mean $\pm \mathrm{SD}$. *, $P<0.05$. (C) Relative expression of Bax mRNA in granulosa cells treated with AZD7762. Fold changes were calculated from $\beta$ actin normalized Ct values. The value expressed by each bar represents mean \pm SD. ***, $P<0.001$. (D) Relative expression of Bax protein. The total amount of $\beta$-actin present in the lower set of lanes was used to standardize the amount of Bax. The same batch of protein samples was used in Figure $3 \mathrm{C}$. The value expressed by each bar represents the mean \pm SD. a vs. b, indicate statistical difference $(P \otimes 0.05)$. 


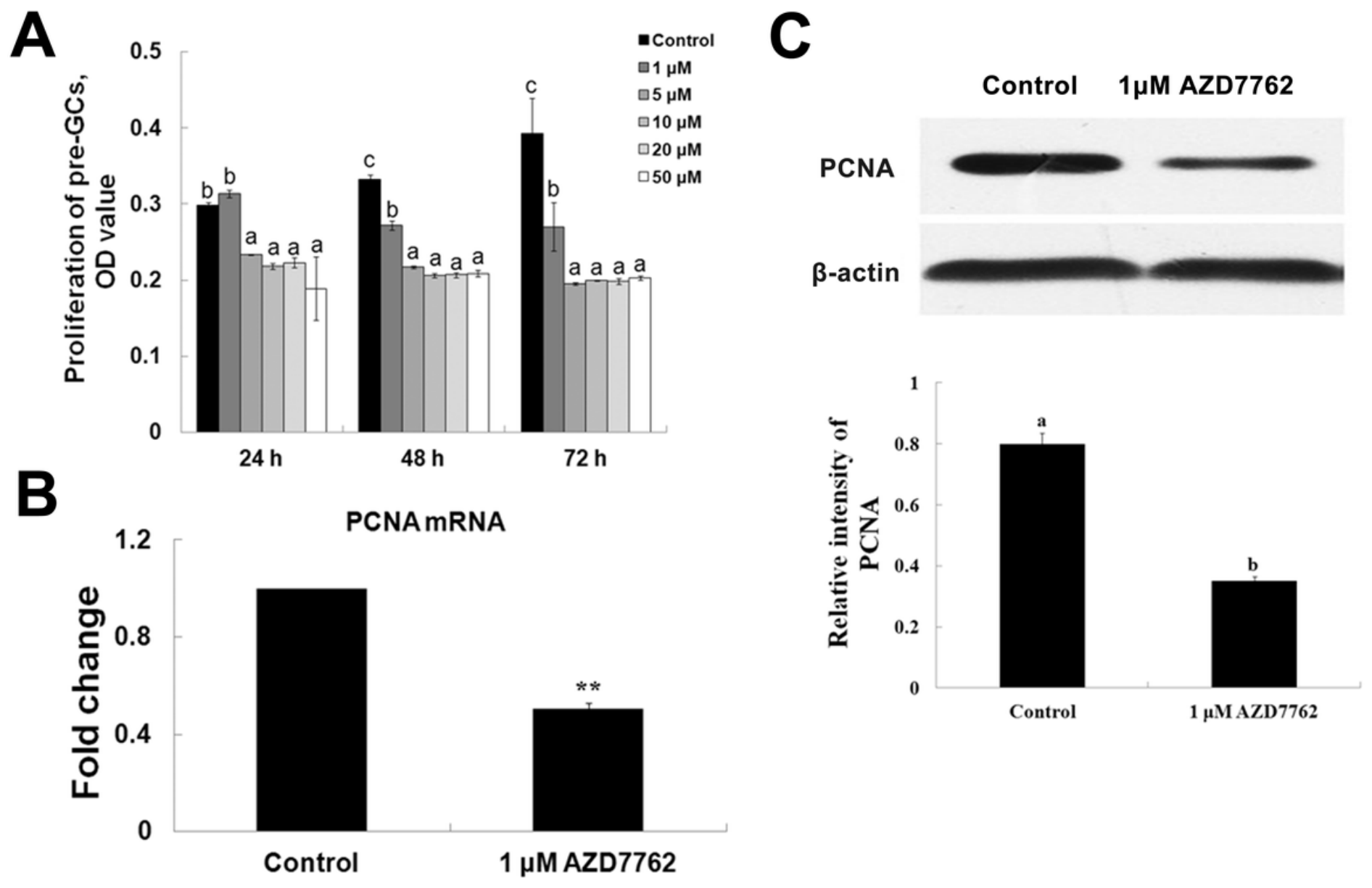

Figure 3

Inhibition of Chk1/2 reduces granulosa cell proliferation. (A) The proliferation of granulosa cells cultured with AZD7762. The value expressed by each bar represents mean \pm SD. $24 \mathrm{~h}$, a vs. $b, P<0.01 ; 48 \mathrm{~h}$, a or $b$ vs. $\mathrm{C}, P<0.001 ; 72 \mathrm{~h}$, a or b vs. $\mathrm{C}, P<0.001$. (B) Relative expression of $P C N A$ mRNA in granulosa cells treated with AZD7762. Fold changes were calculated from $\beta$-actin normalized $\mathrm{Ct}$ values. The value expressed by each bar represents mean $\pm S D$. **, $P<0.01$. (C) Relative expression of $P C N A$ protein. The total amount of $\beta$-actin present in the lower set of lanes was used to standardize the amount of PCNA. The same batch of protein samples was used in Figure 2D, so the lane of $\beta$-actin was the same. The value expressed by each bar represents the mean \pm SD. a vs. b, $P<0.01$. 


\section{Control}

8्ष.

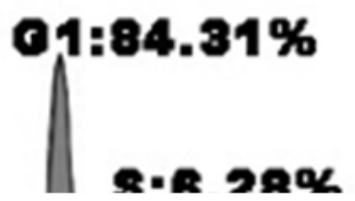

\section{1 pM AZD7762}

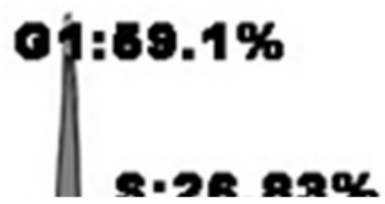

Figure 4

Inhibition of Chk1/2 arrested cell cycle at G2 stage. (A) The cell cycle of pre-GCs cultured with $0 \mu \mathrm{M}$ and $1 \mu \mathrm{M}$ AZD7762 for $48 \mathrm{~h}$. The data showed in this figure was one of the repeats. (B) The ratio of the value expressed by each bar represents mean \pm SD. a vs. b, $P<0.001$. 